(2) Open Access Full Text Article

ORIGINAL RESEARCH

\title{
Integrating Refugee Healthcare Professionals In The UK National Health Service: Experience From A Multi-Agency Collaboration
}

This article was published in the following Dove Press journal:

Advances in Medical Education and Practice

\author{
Mohsin Faysal Butt (iD) ${ }^{1,2}$ \\ Louise Salmon (iD ${ }^{3}$ \\ Fahira Mulamehic ${ }^{4}$ \\ Avelyn Hixon ${ }^{2}$ \\ Abdul Rehman Moodambail ${ }^{5}$ \\ Sandy Gupta ${ }^{2}$ \\ 'Barts and the London School of \\ Medicine and Dentistry, Queen Mary \\ University of London, London EI 2A], \\ UK; ${ }^{2}$ Cardiology Department, Whipps \\ Cross University Hospital, Barts Health \\ NHS Trust, London EII INR, UK; \\ ${ }^{3}$ Refugee Assessment and Guidance Unit \\ (RAGU), London Metropolitan \\ University, London, UK; ${ }^{4}$ British Refugee \\ Council, London, UK; ${ }^{5}$ Paediatrics \\ Department, Newham University \\ Hospital, Barts Health NHS Trust, \\ London EI3 8SL, UK
}

Purpose: Refugee healthcare professionals (RHPs) may encounter several barriers to employment upon moving to the UK, such as conversion of professional qualifications and a lack of familiarity with the recruitment process. The Building Bridges Programme (BBP) is a London-based multi-agency collaboration which helps refugee healthcare professionals seek employment in the UK National Health Service (NHS).

Methods: We have kept an electronic database of all RHPs who have participated in the BBP from October 2009 to March 2018. Data collected include gender, language spoken, country of initial medical qualification, immigration status, religion, ethnicity and professional work experience. In this paper, we focus on employment outcomes and determine the proportion (\%) of RHPs joining the BBP who enter employment in the NHS.

Results: Between October 2009 and March 2018, the BBP supported 372 refugee doctors, 42 refugee pharmacists, 69 refugee dentists, 25 refugee biomedical scientists, 4 refugee physiotherapists and 83 refugee nurses. The following are the results for the RHPs who settled into a registered NHS position appropriate to their (home country) professional qualifications: 98/372 (26\%) doctors, 4/42 (10\%), pharmacists, 17/69 (25\%) dentists, 1/25 (9\%) biomedical scientists, $1 / 4$ (25\%) physiotherapists and 2/83 (2\%) nurses. The following are the results for the RHPs who settled in associated healthcare profession positions: 109/372 (29\%) doctors, 16/42 (38\%) pharmacists, 12/69 (17\%) dentists, 10/25 (40\%) biomedical scientists, 3/4 (75\%) physiotherapists and 34/83 (41\%) nurses.

Conclusion: The BBP provides a useful model that is transferable to other countries. Future studies assessing the utility of such programmes should ensure that the long-term employment outcomes of RHPs are more closely tracked. A key limitation of this paper is the absence of a control group of participants who did not join the BPP, which would help to conclusively demonstrate whether participants who joined our programme had a statistically significant improvement in employment outcomes.

Keywords: refugees, curriculum development, education, employment

\section{Introduction}

The National Health Service (NHS) - the public sector organisation providing statefunded healthcare in the United Kingdom (UK) - is facing a recruitment and retention crisis. ${ }^{1}$ Rising workloads, worsening morale, the NHS pay cap (which has seen doctors' pay fall by up to $17 \%$ in recent years), and concerns around work-life balance are likely factors contributing to healthcare professionals taking time out from training or leaving the NHS altogether. ${ }^{2}$ Overseas healthcare
Correspondence: Mohsin Faysal Butt Barts and the London School of Medicine and Dentistry, Queen Mary University of London, London EI 2AJ, UK

Email mohsinfaysalbutt@doctors.org.uk 
professionals, some of whom are refugees, have the potential to occupy vacant posts. According to statistics from the United Nations High Commissioner for Refugees, there were 126,0720 refugees in the UK in $2018 .{ }^{3}$ Recent statistics show that $69 \%$ of UK hospitals are actively recruiting abroad for doctors or nurses ${ }^{4}$ and over one in three doctors on the UK General Medical Council (GMC) register have gained their primary medical qualification from abroad. ${ }^{5}$

For many overseas healthcare professionals, starting a new job in a new country can be challenging: they must learn new medicolegal frameworks, training systems, skills, guidelines, and negotiate working relationships with other professionals. ${ }^{6}$ These challenges are multiplied manifold for healthcare professionals who arrive as refugees: some have faced persecution and trauma in their homeland, many have lost relevant paperwork, and all are now in a system of healthcare to which they are unfamiliar. ${ }^{7}$ Refugee healthcare professionals (RHPs) need to have successfully applied for asylum in order to receive refugee status. Unfortunately, the asylum system can enforce long-term unemployment, which can lead to a lack of confidence and deskilling, meaning RHPs face distinct disadvantages when they try to resume their career in the UK.

In response to the challenges faced by RHPs, the Building Bridges Programme (BBP) has been established: a multi-agency collaboration which supports the integration of refugee doctors, nurses, dentists, pharmacists, physiotherapists and biomedical scientists into the NHS. The BBP is a partnership between three organisations. The Refugee Assessment and Guidance Unit (RAGU) is based at London Metropolitan University, which provides the main portal for progression through the BBP and provides careers and employment support for doctors, nurses, dentists, pharmacists, physiotherapists and biomedical scientists from assistant level through to post-registration. The British Refugee Council (UK charity number: 1014576) provides advice and support exclusively to refugee doctors and helps prepare them for the Professional and Linguistic Assessments Board (PLAB) examinations and the GMC language requirements - either the International English Language Testing System (IELTS) or Occupational English Test (OET). Glowing Results LLP provides tailored English Language courses to help RHPs achieve the required IELTS or OET scores as prescribed by regulating bodies.

The BBP is supported by several ancillary organisations: Whipps Cross University Hospital (which has itself been running structured clinical observership placements for refugee doctors since 2007); Newham University Hospital; the Professional Support Unit of Health Education England's London Postgraduate Medical and Dental Education school; and 60 primary care practices. After passing the IELTS/OET and PLAB part 2 exams, refugee doctors embark on a 12-week clinical observership placement at Whipps Cross and Newham University Hospitals, which allows them to gain an overview of medical processes and systems in the UK. A YouTube video outlining refugee doctors' experiences of the clinical observership placements provided by Whipps Cross and Newham University Hospitals and the communication and cross-cultural issues refugee doctors need to be aware of is available by the following link: https://youtu.be/W-R3y99SWmM.

The London Professional Support Unit (formerly the London Deanery) runs the Clinical Apprenticeship Scheme (CAPS), which helps refugee doctors access their first NHS post as junior (foundation year 2) doctors - a post equivalent in seniority to a hospital post which UK medical graduates would hold following 1 year of postgraduate medical training. Lastly, primary care practices host three to four-month clinical observership placements for RHPs to gain clinical and non-clinical skills. A selection of the learning topics covered by the BPP is outlined in Table 1.

\section{Methodology}

We have kept an electronic database of all RHPs who have participated in the BBP from October 2009 to March 2018 and, where possible, have followed them up to the point where they entered employment. Data in the database are used for statistical and contractual reporting purposes and include information on gender, language spoken, country of initial medical qualification, immigration status, religion, ethnicity, professional work experience and last

Table I Learning Topics Covered In The Core Curriculum Of The Building Bridges Programme

\begin{tabular}{|l|l|}
\hline I. & Orientation to the National Health Service \\
\hline 2. & Preparing targetted CVs for jobs in healthcare \\
\hline 3. & Identifying strengths and weaknesses \\
\hline 4. & The value of volunteering \\
\hline 5. & Understanding UK work culture \\
\hline 6. & Writing a job application \\
\hline 7. & $\begin{array}{l}\text { Succeeding at a job interview } \\
\text { Creating a clinical attachment portfolio }\end{array}$ \\
\hline
\end{tabular}


known employment. In this paper, we focus specifically on employment outcomes and determine the (\%) proportion of refugee doctors, dentists, pharmacists, physiotherapists and nurses joining the BBP who re-enter their respective healthcare position once settled in the UK. We also determine the (\%) proportion of RHPs joining the BBP who settle in an associated healthcare profession position. The inclusion criteria for joining the BBP are listed in Table 2 .

All healthcare professionals joining the BPP sign a consent form confirming that their data can be used for statistical purposes, project evaluation and contractual reporting. The outcomes contained in this manuscript would not be classified as research as per the definition provided by the UK Policy Framework for Health and Social Care Research: http://www.hra-decisiontools.org.uk/research/. An independent ethical adviser at Queen Mary University of London confirmed that the consent form is appropriate to the work being conducted and provided further clarity that this work is considered a service evaluation and not scientific research (proof available upon request). The confidentiality and anonymity of participants is guaranteed. There is no potential harm to participants as a result of this publication.

\section{Results}

The RHPs involved in the BBP originated from 31 different countries: Afghanistan, Iran, Iraq, Sudan and Syria were the most frequently represented. The period out of practice varied from a minimum of 1 to 17 years. The career outcomes for refugee doctors, pharmacists, dentists, physiotherapists and nurses from October 2009 to March 2018 using last given information are listed in Tables 3 and 4. Between October 2009 to March 2018, the BBP supported 372 refugee doctors, 42 refugee pharmacists, 69 refugee dentists, 25 refugee biomedical scientists, 4 refugee physiotherapists and 83 refugee nurses. The following

Table 2 Inclusion Criteria For Joining The Building Bridges Programme

\begin{tabular}{|c|l|}
\hline I. & $\begin{array}{l}\text { A relevant healthcare degree attained from outside of the } \\
\text { European Union }\end{array}$ \\
\hline 2. & Healthcare professionals with refugee status \\
\hline 3. & $\begin{array}{l}\text { Healthcare professionals with (i) indefinite leave to remain (ILR), } \\
\text { (ii) exceptional leave to remain (ELR), (iii) humanitarian } \\
\text { protection or (iv) discretionary leave }\end{array}$ \\
\hline 4. & Asylum seekers with permission to work \\
\hline 5. & Spouses of refugees \\
\hline
\end{tabular}

Table 3 Career Outcomes For Refugee Doctors From October 2009 To March 2018 Using Last Given Information (the Most Recent And Most Senior Post Known Is Recorded)

\begin{tabular}{|l|l|l|l|l|}
\hline & \multicolumn{4}{|l|}{ Refugee Doctors $\mathbf{n}=\mathbf{3 7 2}$} \\
\hline & $\begin{array}{l}\text { Clinical } \\
\text { apprenticeship } \\
\text { scheme jobs }^{\mathrm{a}}\end{array}$ & $\begin{array}{l}\text { Doctors } \\
\text { in } \\
\text { training } \\
\text { jobs }^{\mathrm{b}}\end{array}$ & $\begin{array}{l}\text { Doctors in } \\
\text { a non- } \\
\text { training post }\end{array}$ & $\begin{array}{l}\text { Associated } \\
\text { healthcare } \\
\text { professions }^{\mathrm{c}}\end{array}$ \\
\hline Total & 65 & 8 & 25 & 109 \\
\hline
\end{tabular}

Notes: a Equivalent in seniority to a hospital post which UK medical graduates would

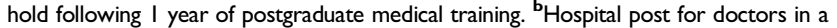
structured pathway to becoming a specialist, i.e. attending/consultant physician. ${ }^{c}$ Healthcare assistants, phlebotomists, nursing assistants, therapy assistants, nurse assistants, pharmacy assistants, medical advocates, medical lab assistants, radiology assistants, note summarisers or medical receptionists.

are the results for the RHPs who settled in a registered NHS position appropriate to their (home country) professional qualifications: 98/372 (26\%) doctors (see Table 3); 4/42 (10\%), pharmacists, 17/69 (25\%) dentists, 1/25 (9\%) biomedical scientists, $1 / 4$ (25\%) physiotherapists and 2/83 (2\%) nurses (see Table 4). The following are the results for the RHPs who settled in associated healthcare profession positions: 109/372 (29\%) doctors, 16/42 (38\%) pharmacists, 12/69 (17\%) dentists, 10/25 (40\%) biomedical scientists, $3 / 4$ (75\%) physiotherapists and 34/83 (41\%) nurses (see Table 4). One hundred and ten structured clinical observership courses were completed through co-operation with Whipps Cross and Newham University Hospitals.

\section{Discussion}

The BBP aims to support the integration of RHPs into the NHS workforce by enabling the understanding of workbased cultural and linguistic competence, clinical and employability training, and work experience. To our knowledge, we are the first London-based programme to support RHPs from varied healthcare professional backgrounds without an exclusive focus on helping refugee doctors. Given our programme's niche, there are no standards against which to judge our project as, to our knowledge, no similar projects exist at present. Exclusive support for refugee doctors by way of structured clinical attachments in NHS hospitals ${ }^{8}$ and multi-agency collaborations coordinated by the London Deanery ${ }^{9}$ have been described in the literature, but unlike our project, neither of these initiatives have supported nurses, dentists, pharmacists, physiotherapists and biomedical scientists.

Given the programme's longevity and the large number of RHPs that have partaken $(\mathrm{n}=595)$, it has proven 
Table 4 Career Outcomes For Refugee Pharmacists, Dentists, Physiotherapists And Nurses From October 2009 To March 2018 Using Last Given Information (The Most Recent And Most Senior Post Known Is Recorded)

\begin{tabular}{|c|c|c|c|c|c|c|c|c|c|c|}
\hline & \multicolumn{2}{|c|}{$\begin{array}{l}\text { Refugee Pharmacists } \\
n=42\end{array}$} & \multicolumn{2}{|c|}{$\begin{array}{l}\text { Refugee Dentists } \\
n=69\end{array}$} & \multicolumn{2}{|c|}{$\begin{array}{l}\text { Refugee Physiotherapists } \\
n=4\end{array}$} & \multicolumn{2}{|c|}{$\begin{array}{l}\text { Refugee Nurses \& } \\
\text { Midwives } \\
n=83\end{array}$} & \multicolumn{2}{|c|}{$\begin{array}{l}\text { Refugee Biomedical } \\
\text { Scientists } \\
\mathrm{n}=25\end{array}$} \\
\hline & $\begin{array}{l}\text { Registered } \\
\text { job as a } \\
\text { pharmacist }\end{array}$ & $\begin{array}{l}\text { Associated } \\
\text { healthcare } \\
\text { professions }^{\mathrm{a}}\end{array}$ & $\begin{array}{l}\text { Registered } \\
\text { job as a } \\
\text { dentist }\end{array}$ & $\begin{array}{l}\text { Associated } \\
\text { healthcare } \\
\text { professions }^{\mathrm{a}}\end{array}$ & $\begin{array}{l}\text { Registered job } \\
\text { as a } \\
\text { physiotherapist }\end{array}$ & $\begin{array}{l}\text { Associated } \\
\text { healthcare } \\
\text { professions }^{\mathrm{a}}\end{array}$ & $\begin{array}{l}\text { Registered } \\
\text { job as a } \\
\text { nurse }\end{array}$ & $\begin{array}{l}\text { Associated } \\
\text { healthcare } \\
\text { professions }^{\mathrm{a}}\end{array}$ & $\begin{array}{l}\text { Registered } \\
\text { job as a } \\
\text { biomedical } \\
\text { scientist }\end{array}$ & $\begin{array}{l}\text { Associated } \\
\text { healthcare } \\
\text { professions }^{\mathrm{a}}\end{array}$ \\
\hline Total & 4 & 16 & 17 & 12 & 1 & 3 & 2 & 34 & I & 10 \\
\hline
\end{tabular}

Notes: ${ }^{a}$ Healthcare assistants, phlebotomists, nursing assistants, therapy assistants, nurse assistants, pharmacy assistants, medical advocates, medical lab assistants, radiology assistants, note summarisers or medical receptionists.

challenging to know the long-term employment history for many RHPs. Indeed, once RHPs move into employment, they often do not want to be identified by their refugee status or the period when support was required. ${ }^{9}$ Similar challenges in tracking the precise employment history of RHPs have been reported by Ong et $\mathrm{al}^{9}$ who narrated the initiatives taken by the London Deanery (Postgraduate Department of Medical and Dental Education, London University) over 8 years in assisting refugee doctors back into medical employment. With the exception of refugee pharmacists (none of whom were lost to follow-up and $100 \%$ gained employment in the NHS), $52 \%$ of pharmacists, $58 \%$ of dentists, $57 \%$ of nurses/midwives, $56 \%$ of biomedical scientists and $44 \%$ of doctors in this service evaluation were lost to follow-up and we are unable to provide details on their most recent employment status. Therefore, it is possible that the proportion of RHPs (see Tables 3 and 4) who joined the BPP from October 2009 to March 2018 and settled in a registered NHS post are minimum percentages.

Several studies have identified a range of practical problems that make it difficult for RHPs to take the required steps towards finding employment in a foreign country, including a lack of appropriate information, lack of a clear route through the system and isolation from support networks. ${ }^{7,10}$ The BBP, through providing a core curriculum (see Table 1), clinical attachments and ongoing pastoral support to RHPs, aims to offer an antidote to these problems. From our discussions with RHPs, personal and health difficulties represented one of the greatest barriers to entering employment in the UK. Many RHPs on the BBP have suffered from the psychological burden of having to leave their homeland and their support networks, often expressing a sense of loss of their own personal future in medicine. Feelings of frustration and isolation from peers, especially from the medical profession, have been reported in qualitative interviews with refugee doctors. ${ }^{10}$ RHPs who joined the BBP found it particularly challenging to adapt to the socratic model of teaching and learning in the UK, which was compounded by the cultural differences - such as the emphasis on multidisciplinary team working in westernised healthcare systems, and the challenges of navigating the idiosyncracies of the English Language.

A key limitation of this study is the lack of a control group; hence, we are unable to conclusively demonstrate whether RHPs who joined the BPP were statistically more likely to gain employment in the NHS. Future research groups may wish to study the long-term career outcomes of all RHPs who express an interest in joining similar programmes and compare the employment outcomes of participants who successfully complete the programme vs those who do not enroll. It would also be interesting for future studies to distil the precise factors, or indeed the interplay of factors, which had the most impact on employment outcomes. A previous study has reported that gender, country of origin, language and country of initial medical qualification, time since last practiced, and family and personal responsibilities, can impact a successful return to the medical profession for refugee doctors. ${ }^{9}$

\section{Conclusion}

RHPs can play an important role in the need for a skilled, diverse healthcare workforce. Work-based training programmes can help RHPs overcome obstacles to employment and introduce RHPs to the training system, medicolegal frameworks and provide pastoral support. Future studies assessing the utility of such programmes should ensure that the long-term employment outcomes of 
RHPs are more closely tracked, although we recognise the challenges of doing so given that RHPs may not want to be associated with their previous refugee status. A key limitation of this paper is the absence of a control group of participants who did not join the programme, which would conclusively demonstrate whether participants who joined the BPP were statistically more likely to seek employment in the NHS. Nevertheless, despite the limitations of this evaluation, our findings are worth disseminating, given the evidence base for such programmes working with RHPs is inadequate. The BBP provides a useful model that is transferable to other countries and we hope that this paper spurs other groups to establish similar programmes.

\section{Abbreviations}

BPP, Building Bridges Programme; CAPS, clinical apprenticeship programme; GMC, General Medical Council; IELTS, International English Language Testing System; NHS, National Health Service; OET, Occupational English Test.

\section{Ethical Approval}

All healthcare professionals joining the Building Bridges Programme sign a consent form confirming that their data can be used for statistical purposes, project evaluation and contractual reporting. The outcomes contained in this manuscript would not be classified as research as per the definition provided by the UK Policy Framework for Health and Social Care Research: http://www.hra-decision tools.org.uk/research/. An independent ethical adviser at Queen Mary University of London confirmed that the consent form is appropriate to the work being conducted and provided further clarity that this work is considered a service evaluation and not medical research (proof available upon request). The confidentiality and anonymity of participants is guaranteed. There is no potential harm to participants as a result of this publication.

\section{Acknowledgments}

The authors would like to acknowledge Dr Stephen Nickless, a retired General Practitioner, for facilitating the Professional Development Group for refugee doctors on the Building Bridges Programme. Louise Lemoine and Anthony Cleary, volunteers, for helping to prepare refugee doctors for the English language tests. Dr Rupal Shah, Associate Dean (Multiprofessional Faculty Development Unit, Professional Development Team, London and South East) and Dr Mohammad Alam (Training programme Director of "Return To Practice", Barts Health NHS Trust) for providing guidance and practical support to refugee doctors accessing the Clinical Apprenticeships Scheme. Rebecca Fynn and Vaishali Joshi for co-ordinating the structured work placements for refugee doctors at Whipps Cross University Hospital, Barts Health NHS Trust. The authors also thankful for the assistance received from the consultants and medical education departments based at Newham University and Whipps Cross University Hospitals, Barts Health NHS Trust.

\section{Disclosure}

The authors report no conflicts of interest in this work.

\section{References}

1. Moberly T. Specialty training vacancies increase by $30 \%$ in a year. BMJ. 2017;358:j3410. doi:10.1136/bmj.j3410

2. Staffing Crisis in NHS Laid Bare, as New BMA Analysis Shows that Three Quarters of Medical Specialities Face Shortage of Doctors. The BMA. The British Medical Association; 2018. Available from: https://www.bma.org.uk/news/media-centre/press-releases/2017/sep tember/staffing-crisis-in-nhs-laid-bare. Accessed February 5, 2019.

3. Refugees UNHCf. Asylum in the UK. United Nations; 2019. Available from: https://www.unhcr.org/uk/asylum-in-the-uk.html. Accessed August 15,2019

4. Hughes D, Clarke V. Thousands of NHS posts lie vacant. BBC; 2016. Available from: https:/www.bbc.com/news/health-35667939. Accessed February 5, 2019.

5. GMC. General Medical Council. List of registered medical practitioners; 2018. Available from: https://www.gmc-uk.org/about/what-we-do-andwhy/data-and-research/gmc-data-explorer. Accessed February 05, 2019.

6. Valero-Sanchez I, McKimm J, Green R. A helping hand for international medical graduates. BMJ. 2017;359:j5230. doi:10.1136/bmj. j5230

7. Huijskens EG, Hooshiaran A, Scherpbier A, van der Horst F. Barriers and facilitating factors in the professional careers of international medical graduates. Med Educ. 2010;44(8):795-804. doi:10.1111/ j.1365-2923.2010.03706.x

8. Ong YL, Gayen A. Helping refugee doctors get their first jobs: the pan-London clinical attachment scheme. Hosp Med. 2003;64(8):488490.

9. Ong YL, Trafford P, Paice E, Jackson N. Investing in learning and training refugee doctors. Clin Teach. 2010;7(2):131-135. doi:10.1111/ j.1743-498X.2010.00366.x

10. Cohn S, Alenya J, Murray K, Bhugra D, De Guzman J, Schmidt U. Experiences and expectations of refugee doctors: qualitative study. $\mathrm{Br}$ J Psychiatry. 2006;189:74-78. doi:10.1192/bjp.bp.105.010975 


\section{Publish your work in this journal}

Advances in Medical Education and Practice is an international, peerreviewed, open access journal that aims to present and publish research on Medical Education covering medical, dental, nursing and allied health care professional education. The journal covers undergraduate education, postgraduate training and continuing medical education including emerging trends and innovative models linking education, research, and health care services. The manuscript management system is completely online and includes a very quick and fair peer-review system. Visit http://www.dovepress.com/testimonials.php to read real quotes from published authors.

Submit your manuscript here: http://www.dovepress.com/advances-in-medical-education-and-practice-journal 